\title{
Biofuel Production by Fermentation of Water Plants and Agricultural Lignocellulosic by-Products
}

\author{
Yaakov Anker ${ }^{1}$, Faina Nakonechny ${ }^{2}$, Betty Niazov ${ }^{2}$, Svetlana Lugovskoy ${ }^{2}$ and Marina Nisnevitch ${ }^{2}$ \\ ${ }^{1}$ Environmental Research, Regional R\&D Center, Ariel University, Israel \\ ${ }^{2}$ Department of Chemical Engineering, Biotechnology and Materials, Ariel University, Israel
}

\begin{abstract}
While at present most energy crops are depriving human feedstock, fermentation of agricultural residues and fast growing water plants possesses a good prospect to become a significant source for bio-fuel; as both substrates are widely available and do not require agricultural areas. Water hyacinth for instance can be cultivated in fresh, brackish or wastewater and owing to its rapid growth and availability. Since owing to its natural abundance it is considered to be an invasive plant in most continents, its utilization and use as a renewable energy source may also contribute for its dilution and control. Agricultural lignocellulosic surplus by-products are also a promising fermentable substrate for bioethanol production, as it decreases both disposal expenses and greenhouse gases emissions. This paper describes a scheme and methodology for transformation of any lignocellulosic biomass into biofuel by simple cost effective operation scheme, integrating an innovative process of mechanochemical activation pre-treatment followed by fermentation of the herbal digest and ethanol production through differential distillation. Under this approach several complex and costly staged of conventional ethanol production scheme may be replaced and by genetic engineering of custom fermenting microorganisms the fermentation process becomes a fully continuous industrial process.
\end{abstract}

\section{Introduction}

Despite the development of new fossil fuels recovery techniques, reducing production costs; ethanol production is increasing, owing to its positive environmental impact and economic benefits. The notion of ethanol advantages over fossil fuels have led to implementation programs in 64 countries, whereas in the USA and Brazil its portion is already greater than $10 \%$ (Fig. 1) and in the EU the $10 \%$ bar is scheduled to 2020 [www.afdc.energy.gov/data/].

World production of ethanol as transportion fuel increased between 2000 and 2007 from 17 billion to more than 52 billion litres, and in 2011 its production reached 84.6 billion litres [1-2]. Most cars in the U.S.A. can consume blends of gasoline fuel with up to $10 \%$ ethanol, and in Brazil the fuel blend consists from $25 \%$ ethanol and $75 \%$ gasoline. By December 2011 in Brazil there already were 14.8 million dual-fuel vehicles and 1.5 million dual-fuel motorcycles, which regularly were using $100 \%$ ethanol fuel [3].

The most common source for biofuel today are sugarrich feedstock's, including sugarcane, sugar beet and various fruits, which are converted into ethanol with relatively high yield. However, large-scale expansion of these sources is limited by the feedstock prices. The choice of such a feedstock for ethanol production is problematic since the biomass requirements either directly or indirectly compete with food crops for arable land resources. For this reason, production of ethanol from lignocellulosic surplus by-products (e.g. wood residue, sugarcane bagasse, corn fibres, rice straw, cassava waste etc.) has received widespread interest owing to their availability, abundance and relatively low cost [4-6]. A parallel trend is utilization of marginal lands for cultivation of CAM bioenergy crops, such as Agave and Opuntia [7]. Nevertheless, these of other CAM plants are also considered as possible human feed source and once cultivated these marginal lands are no longer marginal, but rather farmlands.

Aquatic plants belong to another group of promising renewable energy resource. The use of aquatic plants has benefits, such as, an absence of competition with grains and vegetables on arable farmland, low cultivation expenses and the potential of artificial water reservoirs and aeration pools purification. The use of free-floating aquatic plants for self-remediation of hazardous organic compounds and heavy metals from concomitant water is approved by several directives [8].

Water hyacinth (Eichhornia crassipes) as an example is a good potential candidate for ethanol feedstock. Its biomass has about $48 \%$ hemicellulose, $18 \%$ cellulose and $3.5 \%$ lignin $[8]$ and regardless composition variability it is considered to be rich in hemicellulose and with low lignin content [10]. In addition, since it is a typical menace infesting the backwaters in many places around the world [11-12], effective technologies for ethanol 
production from biomass can serve the purpose of aquatic weed removal. Processing biomass into biofuel through the use of high technology and complicated instrumentations may limit their commercialization and industrial applicability, especially for developing countries. Moreover, surplus biomass processing in large scale plants may not be economical owing to the problems in collection, transportation and infrastructural requirements [13]. Localized ethanol production systems may be far more efficient, especially in countries where agriculture is decentralized and the biomass availability is distributed.

Such systems will allow the use of regionally available biomass types, such as agriculture by-products, water hyacinth and other aquatic species and also other types of organic feedstocks. This scenario may also include some economic and social benefits for rural community being less capital intensive and demanding less skilled workforce [14], enabling new mean of employment and income to rural communities.

At present, centralized ethanol production systems are economically obligatory owing to the complex biomass pre-treatment and the enzymatic saccharification (especially the sourcing of enzymes), which pose several technical challenges to distributed localized ethanol industry[15]. These challenges are being addressed in the current paper with the development of a new innovative mechanochemical pre-treatment and in integrative continuous ethanol production operation scheme.

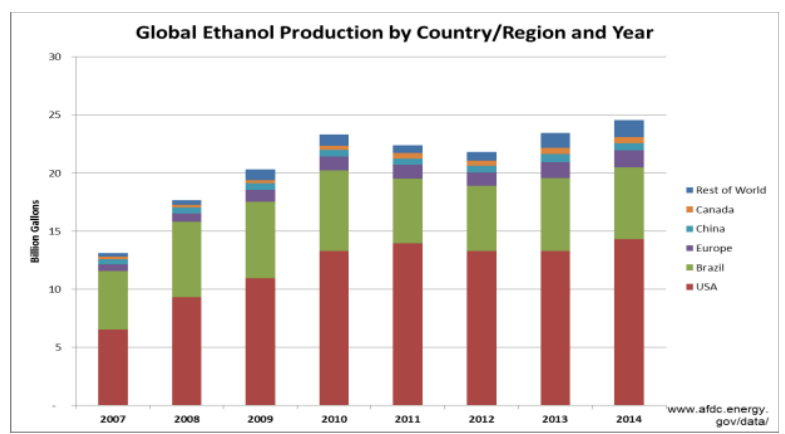

Figure 1. World ethanol production for the years 20042014

\section{Methodology}

An integrative and continuous process was developed for the optimal transformation of water plant biomass and agricultural wastes into ethanol. Following biomass chopping with a rotary blade device a novel mechanochemical fermentation pre-treatment is applied. This treatment replaces most of the costly stages of polysaccharides depletion into monosugars and optimizes the subsequent fermentation process owing to the increase in biomass active surface area [16]. The transformation of the post-treated biomass into ethanol is done by differential microbial fermentation with optimal conditions for fermentation of the monomer sugars into ethanol. At the last stage, an optimal scheme for ethanol recovery and concentration by direct continuous distillation is yet under development.

\subsection{Mechanochemical pretreatment}

Biomass pre-treatment methods may be classified into different categories, e.g. physical, chemical, biological, and combination of these methods [17]. Physical pretreatment alters biomass structure by mechanical stress without additional chemical or biological reagent. Lignocellulosic materials are difficult to process in raw condition; owing to the celluloses, hemicelluloses and lignin, strong linked structure [18]. The pre-treatment process should increase biomass active surface area and pore sizes [19] and also reduce cellulose and hemicellulose degree of crystallinity and polymerization ([17], [20]).

Through the physical rendering of the cellulose and hemicellulose rigid structure, the mechanochemical process can increase their solubility and break them into monomers, making the biomass suitable for fermentation. The mechanochemical process includes pressure based water extraction and graining of the biomass, followed by an activation treatment, which converts the plant's polysaccharides into monosaccharides. The main distinction of polysaccharides from (mono-) oligosaccharides is the presence of the glycoside bond between (mono-) oligosaccharides (Fig. 2). Disruption of these bonds leads to production of monosaccharides: glucose in the case of cellulose (Fig. 2a) and, mainly, xylose in the case of hemicelluloses (Fig. 2b).

Agricultural wastes contain mostly, cellulose and aquatic plants biomass mostly, hemicellulose, making them both suitable for mechanochemical pre-treatment. Polysaccharides transformation into monosaccharides increases the sustenance of nutriment and decreases the biofuel production process fermentation time.

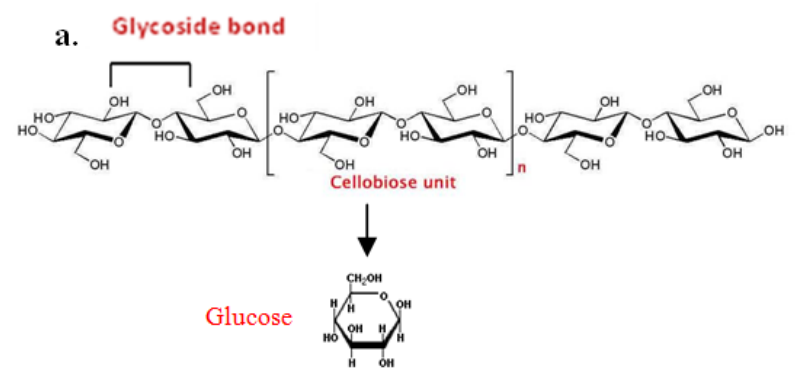

b.
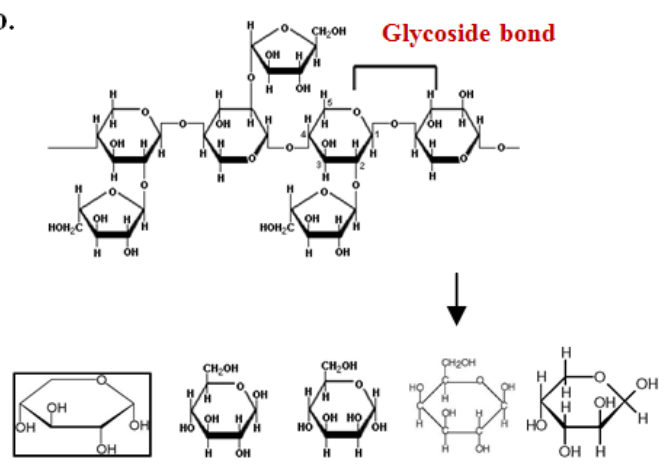

Xylose + Glucose + Mannose + Galactose + Arabinose

Figure 2. Conceptual scheme of polysaccharides' transformation into monosaccharides: a. cellulose and b. hemicellulose. 


\subsection{Fermentation process}

While traditional fermenting yeast (S. cerevisiae) produce ethanol from hexoses, recent genetic engineering has produced microorganisms that ferments pentoses in addition to hexoses into ethanol [21-22]. Several fermenters were tested during the research including: Common baker's yeast Saccharomyces cerevisiae, $S$. cerevisiae NBRC 2346, recombinant bacterial strains $E$. coli KO11, Klebsiella oxytoca, Zymomonas mobilis or a yeast strain Pichia stipitis [23].

The fermentation scheme under development is differentially applying specific fermenters in a sequential fermentation process, allowing optimal ethanol recovery from various biomass substrates.

\section{Results and discussion}

The research consisted of two stages, at the beginning water hyacinth plants from a water plant, cultivation pond (Fig. 3), were processed into homogenous biomass. The plants were harvested and air-dried. The dried plants were divided into three groups: a. plants sliced with a knife, b. plants roughly shredded and the c. group was treated mechanochemically. After that, each group was subjected to two kinds of treatments: acid hydrolysis and heating in aqueous medium in autoclave $\left(121^{\circ} \mathrm{C}, 1 \mathrm{~atm}\right.$, $15 \mathrm{~min})$.

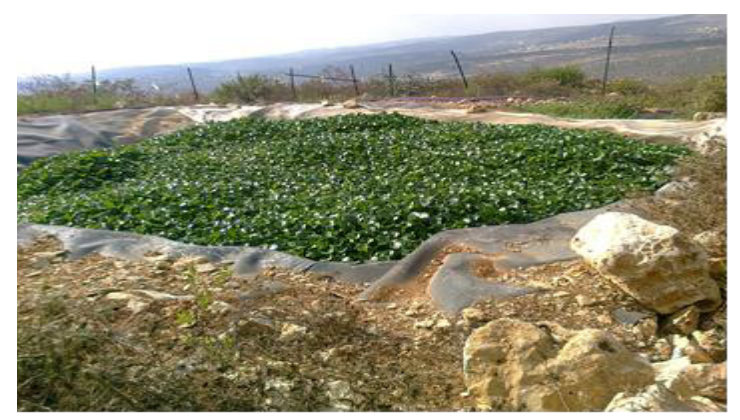

Figure 3. $5 \times 6 \mathrm{~m}$ pond (free-flow wetland), used for wastewater sanitation stage of the Ariel University student dormitories, wastewater reclamation project

The plant biomass was separated from the liquids and xylose concentration was measured by spectrophotometric assay (Fig. 4). As can be seen, after both treatments, by acid ( $1 \%$ sulfuric acid) and by water, the highest xylose concentration was achieved after a short (1-5 minutes) mechanochemical treatment.

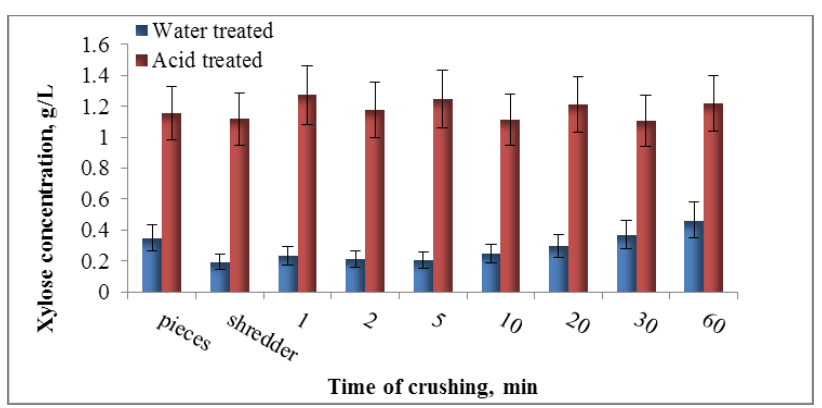

Figure 4. Xylose concentration extracted from $\mathbf{a}, \mathbf{b}$ and $\mathbf{c}$ types water hyacinth biomasses, after acid and aqueous treatments and various stages of milling.
During process optimization, the biomass to milling balls ratio and milling speed were tested in various constellations (Fig. 5). This procedure determined the optimal milling speed $(650 \mathrm{rpm})$, temperature $\left(90^{\circ} \mathrm{C}\right.$ optimal and $55^{\circ} \mathrm{C}$ nominal) and mass to balls ratio (1/40).

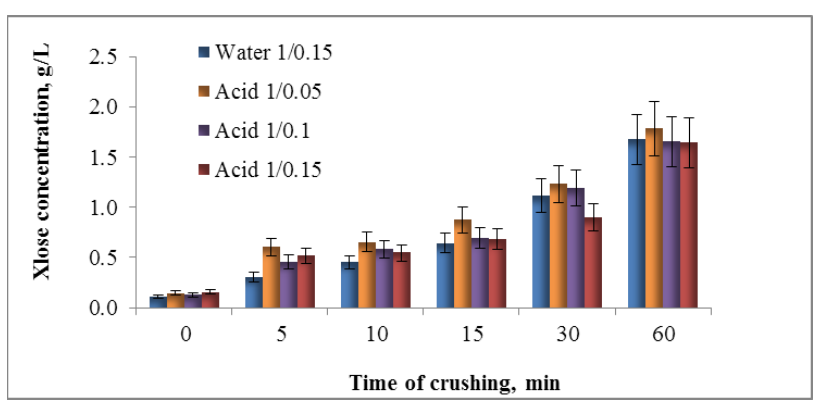

Figure 5. The results of xylose concentration after water and acid treatment (in several acid/biomas ratios) with $1 / 40$ biomass to balls ratio and milling speed of $650 \mathrm{rpm}$.

Within this stage Pichia stipitis yeast were grown on a xylose containing medium. The growth curve of the yeast showed, that Pichia stipitis cells are capable of using xylose as organic substrate. In addition, other substrates in different combination were also evaluated. The substrates that were evaluated consisted of hydrolyzate synthetic fermentation substrate, Xylose in different concentrations and processed biomass with various xylose concentrations. The mechanochemical process was applied to the water hyacinth biomass and in the following stage to other organic materials. The treatment consisted of three hours duration in 650 RPM and wet biomass to milling balls ratio of $1 / 30$, which was found nominal (vs. 1/40) in the previous research stage.

The fermentation productivity comparison was done both by monitoring the yeast growth curve and measurements of the ethanol concentration (Fig. 6). While the mixture of commercial synthetic reference substrate and water hyacinth biomass yielded the highest ethanol concentrations $(18 \mathrm{~g} / \mathrm{L})$ after eight days the treated water hyacinth biomass alone demonstrated slightly lower concentrations $(16 \mathrm{~g} / \mathrm{L})$ after ten days, which is with about the same economical balance owing to the material price of the commercial substrate.

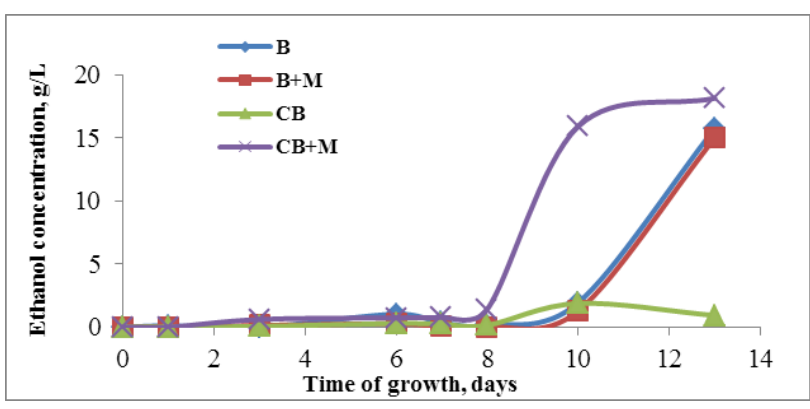

Figure 6. Ethanol production by fermentation with Pichia stipitis yeast in: B- Treated water hyacinth fermentation substrate with $14 \mathrm{~g} / \mathrm{L}$ initial xylose concentration M- synthetic fermentation medium and CB- reference of $14 \mathrm{~g} / \mathrm{L}$ xylose synthetic substrate.

The second research stage was focused on identification and evaluation of various agriculture products and aquatic plants as potential fermentation 
substrates. The suitability evaluation was done through measurements of their sugars combination and lipids and also protein contents; before and after nominal mechanochemical treatment. It was found that protein concentration (Fig. 7) is the most valid parameter for comparison. The results indicates that while protein levels in fruits are not affected by the mechanochemical treatment, grass, which is an equivalent to most surplus agriculture by-products, as well as aquatic plants such as water lettuce (Pistia stratiotes) are susceptible to the treatment, which improves their fermentation potential.

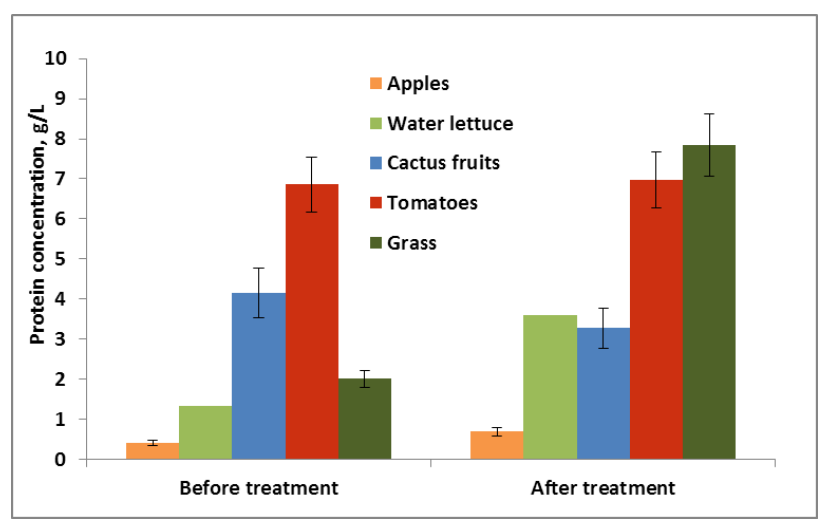

Figure 7. Dissolved protein concentrations, in various organic biomasses, before and after mechanochemical pre-treatment.

\section{Conclusions}

The present study is aimed to apply a simple and reliable process for the bioconversion of water hyacinth and agricultural wastes into ethanol. The proposed approach futile complex operations that are currently essential and as such, are expected to provide the cost efficiency allowing the technology implementation throughout developed and developing countries.

In general, increasing efforts and funds are being dedicated to the development and application of surplus biomass conversion into liquid bio-fuels and in particular ethanol, which provides several advantages over fossil fuels [23]-[24]:

1. Utilization of abundant and inexpensive sources of renewable resources

2. Reduction in greenhouse gas emission and toxic substances

3. Macroeconomic benefits for under-developed rural communities and their social aspect of sustainability

4. Improving national energy security

The possibility of converting aquatic plants and surplus agriculture products into ethanol is currently established in a number of developing countries [10-11]. While the approach advocated here favours distributed production units, such pilot facilities have not yet become industrial [26]. The methodology developed, may economically improve such systems by utilizing vast range of raw materials for ethanol production [27]. Moreover, the environmental impact in such cases will always be positive either through reduction in agriculture wastes or through mitigation of invasive aquatic flora growth [28-29]. In developed and developing countries this approach may be applied as wastewater treatment by aquatic flora grown in wastewater reservoirs and its transformation into biomass suitable for ethanol production [30]. The operation scheme developed throughout this research consists of several stages that may be utilized as basis for the development of continuous system for biomass transformation into ethanol:

1. Biomass chopping

2. Mechanochemical process

3. Differential fermentation

4. Ethanol refinement

At the present R\&D stage, biomass chopping is done by commercial high-speed rotary blade cutter. The mechanochemical process is in an upscaling stage as well as the processed, biomass differential fermentation stage. The final stage of continuous ethanol distillation is also under development, which is being done directly in semiindustrial capacity.

\section{Acknowledgement}

The research is funded by the Israeli ministry of environmental protection.

\section{References}

1. Bringezu S., H. Schütz, M. O'Brien, L. Kauppi, R.W. Howarth and J. McNeely, Report of UNEP (United Nations Environment Programme), Towards Sustainable Production and Use of Resources: Assessing Biofuels (2009).

2. RFA (Renewable Fuels Association), Accelerating Industry Innovation - 2012. Ethanol Industry Outlook (2012).

3. Flavin C., J. L. Sawin, L. Mastny, M. H. Aeck, S. Hunt, A. MacEvitt and P. Stair, Report of American Energy, The renewable path to energy security, Worldwatch Institute and Center for American Progress (2006).

4. Gonzales G., Lopes-Santin J., Caminal G. and Sola C. Dilute acid hydrolysis of wheat straw hemicellulose at moderate temperature: a simplified kinetic model. Biotechnol Bioeng, 28:288-293, (1986)

5. Pessoa Jr. A., Mancilha I.M. and Sato S. Acid hydrolysis of hemicellulose from sugarcane bagasse. Braz. J. Chem. Eng. 14:291-297, (1997).

6. Hu G., J.A. Heitmann and O.J. Rojas, Feedstocks pretreatment strategies for producing ethanol from wood, bark and forest residues, BioResources, 3:270 294, (2008)

7. Yang, L., Lu, M., Carl, S., Mayer, J. A., Cushman, J. C., Tian, E., \& Lin, H., Biomass characterization of Agave and Opuntia as potential biofuel feedstocks. Biomass and Bioenergy, 76, 43-53. doi:10.1016/j.biombioe.2015.03.004, (2015) 
8. Mishima D., Kuniki M., Sei K., Soda S., Ike M. and Fujita M. Ethanol production from candidate energy crops: water hyacinth (Eichhornia crassipes) and water lettuce (Pistia stratiotes L.). Bioresour. Technol. 99:2495-2500, (2008).

9. Nigam J. N. Bioconversion of water-hyacinth (Eichhornia crassipes) hemicellulose acid hydrolysate to motor fuel ethanol by xylosefermenting yeast, J. Biotechnol. 97:107-116, (2002)

10. Abraham M. and Kurup G.M. Pretreatment studies of cellulose wastes for optimization of cellulose enzyme activity. Appl. Biochem. Biotechnol.62:201-211, (1997).

11. EEA, 2012. The impacts of invasive alien species in Europe. EEA Technical Report No. 16/2012. Luxembourg: Publications Office of the European Union.

12. Gichuki J., Omondi R., Boera P., Tom Okorut T., Said Matano A., Jembe T. and Ofulla A. Water hyacinth Eichhornia crassipes (Mart.) SolmsLaubach dynamics and succession in the Nyanza Gulf of Lake Victoria (East Africa): implications forwater quality and biodiversity conservation. The Scientific World Journal 2012, 10 pp.

13. Ganguly A., Das S., Bhattacharya A., Singh P., Chatterjee P. K. and Dey A. Studies on the production of xylose from water hyacinth. Chemical Science, 2(1):1-7, (2013)

14. Aswathy U.S., Sukumaran R. K., Devi G. L., Rajasree K.P., Singhania R. R. and Pandey A. Bioethanol from water hyacinth biomass: An evaluation of enzymatic saccharification strategy. Bioresource Technology, 101:925-930, (2010)

15. Ganguly A., Das S., Dey A., Das R. and Chatterjee P. K. Optimization of xylose yield from water hyacinth for ethanol production using Taguchi Technique. IOSR Journal of Pharmacy and Biological Sciences (IOSR-JPBS), 3(5):1-9, (2012)

16. Harun M.Y., Radiaha A.B.D., Abidina Z.Z. and Yunus R. Effect of physical pretreatment on dilute acid hydrolysis of water hyacinth (Eichhornia crassipes). Bioresource Technology,102:5193-5199, (2011)

17. Silverstein R., Y. Chen, R. Sharma-Shivappa, M. Boyette and J. Osborne, A comparison of chemical pretreatment methods for improving saccharification of cotton stalks, Bioresour. Technol. 98:3000-3011, (2007)

18. Boudet A. M., S. Kajita, J. Grima-Pettenati and D. Goffner, Lignins and lignocellulosics: a better control of synthesis for new and improved uses, Trends Plant Sci, 8:576-581, (2003)

19. Da Costa Sousa L., S.P.S. Chundawat, V. Balan and B.E. Dale, 'Cradle-to-grave' assessment of existing lignocellulose pretreatment technologies, Curr. Opin. Biotechnol. 20:339-347, (2009)

20. Binod P., R. Sindhu, R. Singhania, S. Vikram, L. Devi, S. Nagalakshmi, N. Kurien, R. Sukumaran and A. Pandey, Bioethanol production from rice straw: an overview, Bioresour. Technol. 101:4767-4774, (2010)

21. Dien B. S., Cotta M. A. and Jeffries T.W. Bacteria engineered for fuel ethanol production: current status, Appl. Microbiol. Biotechnol. 63:258-266, (2003)

22. Wooley R., Ruth M., Glassner D. and Sheehan J. Process design and costing of bioethanol technology: a tool for determining the status and direction of research and development. Biotechnol. Prog. 15:794803, (1999)

23. Krahulec S., Kratzer R., Longus K. and Nidetzky B. Comparison of Scheffersomyces stipitis strains CBS 5773 and CBS 6054 with regard to their xylose metabolism: implications for xylose fermentation. Microbiology Open,1:64-70, (2012)

24. Knauf $M$. and Moniruzzaman M. Lignocellulosic biomass processing: A perspective. Int Sugar J. 106:147-150, (2004)

25. Lin Y. and Tanaka S. Ethanol fermentation from biomass resources: current state and prospects. Appl Microbiol Biotechnol. 69:627-642, (2006)

26. Abdullah M. O., Lim S.F., Salleh S.F., Tai T.M., Leo S.L. and Umar A.K. Development of a small-scale reactor system for bioethanol production from agriculture waste geared towards small industries applications in Malaysia. Agriculture.12:12-15, (2011)

27. Hahn-Hägerdal B., Galbe M., Gorwa-Grauslund M. F., Lidén G. and Zacchi G. Bio-ethanol - the fuel of tomorrow from the residues of today. Trends Biotechnol.24:549-556, (2006)

28. Theuri M. Water hyacinth - Can its aggressive invasion be controlled? Environmental Development,7:139-154, (2013)

29. Zhang Y., Zhang D. and Barrett S. Genetic uniformity characterises the invasive spread of water hyacinth (Eichhornia crassipes), a clonal aquatic plant. Molecular Ecology,19:1774-1786, (2010)

30. Sarkar N., Ghosh S.K., Bannerjee S. and Aikat K. Bioethanol production from agricultural wastes: An overview. Renewable Energy, 37:19-27, (2012) 